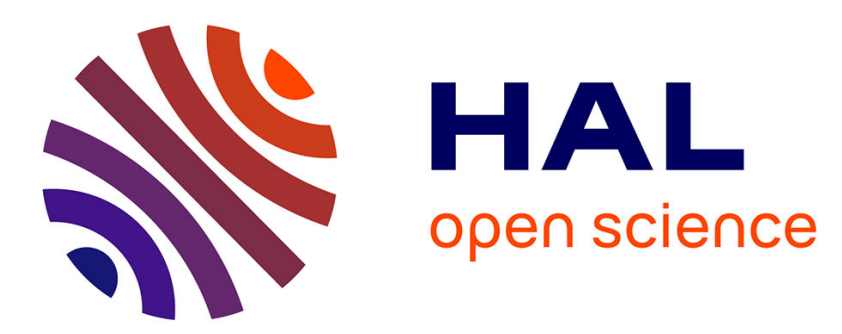

\title{
Use of 1D mechanical and thermal models to predetermine the heat transferable by a thermal interface material layer in space applications
}

Simon Vandevelde, Alain Daidié, Marc Sartor

\section{- To cite this version:}

Simon Vandevelde, Alain Daidié, Marc Sartor. Use of 1D mechanical and thermal models to predetermine the heat transferable by a thermal interface material layer in space applications. Proceedings of the Institution of Mechanical Engineers, Part C: Journal of Mechanical Engineering Science, 2020, pp.095440622091550/1-15. 10.1177/0954406220915508 . hal-02540643

\section{HAL Id: hal-02540643 \\ https://hal.science/hal-02540643}

Submitted on 11 Apr 2020

HAL is a multi-disciplinary open access archive for the deposit and dissemination of scientific research documents, whether they are published or not. The documents may come from teaching and research institutions in France or abroad, or from public or private research centers.
L'archive ouverte pluridisciplinaire $\mathbf{H A L}$, est destinée au dépôt et à la diffusion de documents scientifiques de niveau recherche, publiés ou non, émanant des établissements d'enseignement et de recherche français ou étrangers, des laboratoires publics ou privés. 


\title{
Use of 1D mechanical and thermal models to predetermine the heat transferable by a TIM layer in space applications
}

\author{
Vandevelde Simon \\ CNES (French Space Agency), 18 Avenue Edouard Belin, 31401 Toulouse, France \\ Université de Toulouse, Institut Clément Ader, UMR CNRS 5312, INSA/UPS/ISAE/Mines Albi \\ 3 rue Caroline Aigle 31400 Toulouse, France \\ simon.vandevelde@insa-toulouse.fr \\ Daidié, Alain \\ Université de Toulouse, Institut Clément Ader, UMR CNRS 5312, INSA/UPS/ISAE/Mines Albi \\ 3 rue Caroline Aigle 31400 Toulouse, France \\ alain.daidie@insa-toulouse.fr

\section{Sartor, Marc} \\ Université de Toulouse, Institut Clément Ader, UMR CNRS 5312, INSA/UPS/ISAE/Mines Albi \\ 3 rue Caroline Aigle 31400 Toulouse, France \\ marc.sartor@insa-toulouse.fr
}

\begin{abstract}
This paper proposes the use of $1 D$ basic models to build a design assistance tool capable of evaluating the heat transfer between a third-level electronic packaging and its support, considering a conventional configuration where a Thermal Interface Material (TIM) is placed between these two parts. Using this kind of tool early in the design process may facilitate choices concerning geometry and material. The packaging is modelled by a stepped beam (the equipment) and the interface layer by a nonlinear elastic foundation (the TIM). Considering that the electronic equipment bends under the effect of the forces exerted by the fasteners, the tool makes it possible to determine the contact zone remaining operative after deformation, and the pressure distribution at the interface. Mechanical results are then used to calculate the steady-state heat transfer between the equipment and its support, taking into account the diffusion within the equipment and the TIM, and also the thermal contact resistances, the latter being dependent on the contact pressure. A detailed case study is used to illustrate the utility of the approach. The 1D models are exploited to illustrate the interest of the design assistance tool. The influence of different parameters on the thermal performance is studied and a new innovative proposal is analyzed, which could lead to a significant increase in thermal performance.
\end{abstract}

\section{KEYWORDS}

Thermal Interface Materials (TIMs), Thermal Contact Resistance (TCR), Estimation of contact surface, 1D mechanical and thermal models, Thermal performance, Design assistance tool 


\section{INTRODUCTION}

The increasing power of electronic equipment intensifies the need for highly efficient heat transfer within electronic packaging [1]. Therefore, Thermal Interface Materials (TIMs) are omnipresent at interfaces at different packaging levels and applications [2].

This paper addresses third level packaging of spacecraft assemblies, i.e. electronic equipment items attached to a satellite panel by fasteners. Figure 1 illustrates the type of electronic equipment that is considered here [3], which consists of metal casings intended to receive and protect electronic cards. Fixing legs are arranged on both sides to attach it to the spacecraft with fasteners.

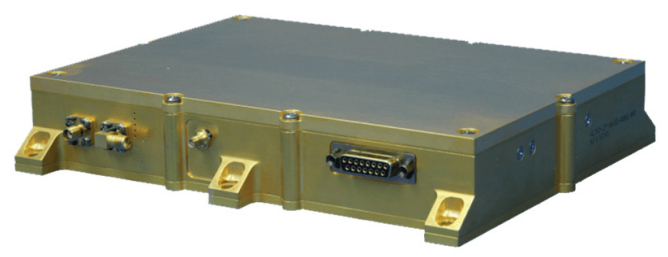

Figure 1. Typical electronic equipment for space application [3]

The problem encountered with these assemblies is a degradation in thermal performance due to mechanical macro-deformations and, in particular, bending of the wall of the equipment that makes contact with the support structure of the satellite. The loads exerted by the fasteners cause large enough deformation of the equipment for the contact with the heat sink to be lost in certain areas of the interface. In the places where the contact is lost, the primary heat transfer path by conduction is interrupted, thus reducing the thermal performance of the assembly, especially for spacecraft applications, where no convection is present due to the environment and radiation cannot provide good thermal coupling. Furthermore, high-end electronics dissipates a considerable amount of power. Permanent damage to equipment is a significant risk, in that it can affect the integrity of the satellite. TIMs address this issue by increasing the contact zone. Figure 2 illustrates the kind of result that can be obtained from Finite Element Analysis (FEA) when a bare interface is compared with an interface including TIM. For a bare interface, contact is only present in the near vicinity of the fasteners. The interposition of a TIM can enlarge the contact zone significantly. Different types of TIMs are commercially available, such as thermal greases, phase change materials, gels, adhesives, particle laden silicones, metallic foils, polymeric TIMs, solder TIMs and even carbon nanotubes [4]. However, the space industry only allows the use of a few of them because of the strict regulations e.g. on outgassing [5]. Only some particle laden silicones, metallic foils and polymeric TIMs are accepted. Particle laden silicones are used in level two packaging, where they remove heat generated by chips and between components or Printed Circuit Boards (PCB). This paper discusses applications in which a thin layer of polymeric TIM is placed under the equipment. 

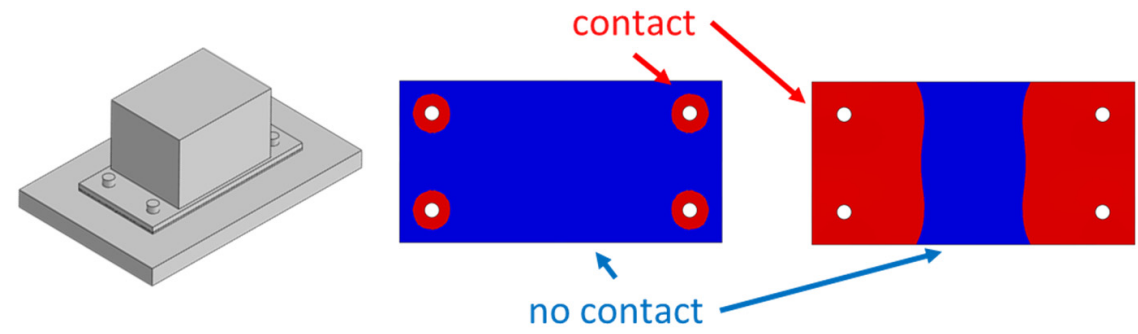

Figure 2. Contact zone of bare interface (left) and interface with polymeric TIM (right)

The temperature of an equipment item cannot be successfully controlled without considering the physical behaviors that govern the heat exchanges between this equipment and its support, foremost among which are the nature and the characteristics of the contact between the two parts. Furthermore, heat transfer through an interface is a complex process since the Thermal Contact Resistance (TCR) depends on various thermal, geometrical and mechanical parameters, as presented in [6]. Both macro- and microscale phenomena may be present for each of these domains [7]. The thermal spreading resistance is extensively studied below, as in [8], and applied to practical case studies concerning electronic packaging, as in [9] and [10]. The sensitivity of different parameters is studied in order to find an optimized design. Lasance concluded that many designers may have a false perception of thermal resistance, which is a complex phenomenon that can only be addressed by formulas [9]. These studies only consider the thermal aspect and, in some ways, the micro-mechanical aspects, as contact resistance is found by contact pressure and deformation of the asperities. Even when a thermomechanical coupling is considered for the calculation of the mechanical deformation and pressure in order to determine the thermal contact resistance, the contact pressure is still considered to be uniformly distributed over the surface [11] or not considered at all [12]. When tackling the problem at a macroscopic level, considering the contact pressure as evenly distributed over the surface would be a risky assumption. This would be far from reality because the distribution of this pressure is very variable [13], becoming zero in the areas where the contact is lost, and such areas can represent the majority of the interface in some assemblies. The study of the areas where the contact actually takes place, at a macroscopic level, has been the subject of numerous works, for example in the field of heat exchangers [14] and in injection molding applications [15]. These works have shown that the performance in terms of heat transfer is highly dependent on the nature and characteristics of these areas. Optimizing the contact status by a finite element method with one-dimensional elements has been the interest of research studies, but without considering the thermal aspects [16].

Since the geometry of the equipment and the choice of materials have significant influence on thermal performance, it is interesting to have a calculation tool at hand that enables the impact of these factors to be evaluated easily. If the results are obtained instantly, sensitivity studies can be carried out at lower cost, making it possible to better understand the relative importance of the different parameters. On the basis of repeated 
experiments, design rules can be identified. Pursuing this objective, the approach adopted in this article is not to provide an extremely precise description of the system studied and the physical phenomena involved. It is rather to propose the most synthetic modeling possible, considering the mechanical and thermal phenomena that appear the most determining. This modeling must allow a quick and inexpensive estimation of the stabilized temperature of the equipment, knowing the power it dissipates. On the basis of the proposed model, it should be possible to develop a computational tool capable of assisting the preliminary design work, a design phase during which it is better to avoid using 2D or 3D models, which would lead to long, complex tasks.

The proposed modeling focuses first on the mechanical behavior of the equipment and the TIM, in order to obtain the areas of contact and the distribution of pressure in these zones. Then, from these results, it endeavors to reproduce the thermal behavior.

It relies on 1D finite elements for mechanical aspects and 1D finite differences for thermal aspects, which lead to simple models that can be implemented and solved with general commercial codes, for example using a Matlab script or VBA macros. Figure 3a schematizes the level of abstraction used to build the model. A stepped beam represents the equipment, placed on a thin layer of TIM. The TIM is placed on a support that acts as a heat sink, this support being considered here as infinitely rigid because its structure is much more rigid than that of the equipment. At both sides, a mechanical load is applied on the fixing legs, representing the bolt load exerted by the fasteners. A heat load is introduced along the center part of the equipment, representing the dissipating components. Figure $3 \mathrm{~b}$ illustrates the results: the equipment and TIM are deformed and a temperature profile is present. Due to the deformation, there is a loss of contact in the center of the equipment. Heat conduction to the heat sink is only possible in the contact zone: in the vicinity of the feet. The geometry and material characteristics are fully parametrized. So the user can easily iterate the model and evaluate the changes in order to converge on an optimized choice of geometry or material, as illustrated in section 4. Also, the proposed tool can study new concepts, such as placing a thicker TIM patch were contact is normally lost. Section 2 gives details of the implementation of the mechanical and thermal model. The model is then validated in section 3 by a commercially available finite element software package.
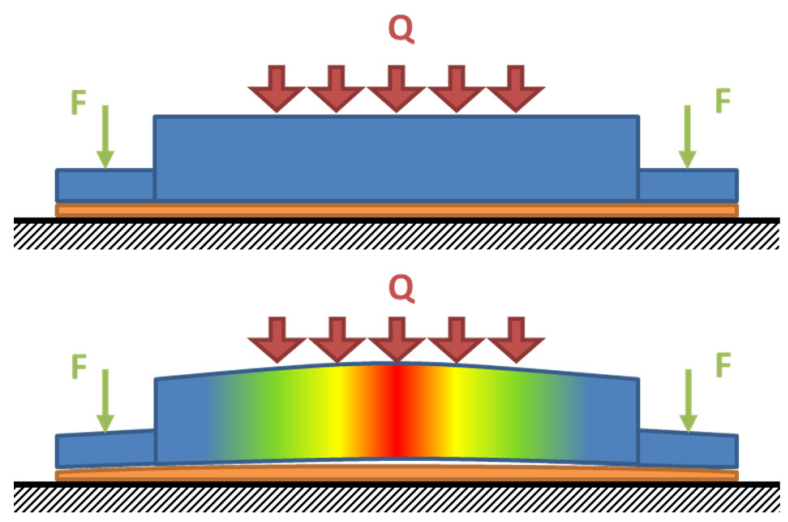

Figure 3. Ideal behavior (top) and actual behavior (bottom) 


\section{PROPOSED MODEL}

The model simplifies the real world to one-dimensional problems considering several hypotheses. The geometry is illustrated in Figure 4; it is a simplified geometry derived from an actual application illustrated in Figure 1.

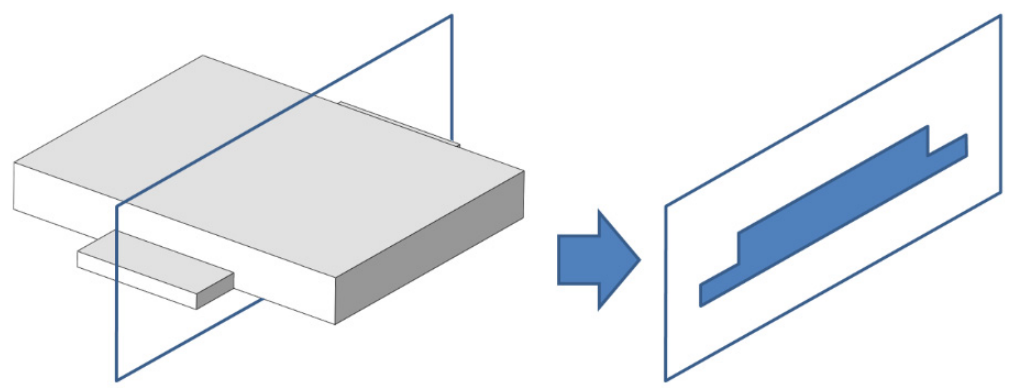

Figure 4. Simplified geometry of 1D model

(1) The geometry is considered to be symmetric about a plane, and is projected onto this plane as illustrated by Figure 4. (2) There is no coupling between the mechanical and the thermal models. Although the materials do have temperature dependent parameters, simulations show that, in most cases, these effects are secondary. (3) Thermoelasticity and damage are not yet considered. A description and implementation of the thermomechanical cyclic behavior is given in [17]. (4) The equipment is modelled by onedimensional elastic beam elements with two degrees of freedom (flexion in the plane). (5) The TIM is represented by a Winkler elastic foundation. The Winkler foundation is modified to account for the nonlinear mechanical behavior of the TIM. (6) Fasteners are not modeled but replaced by uniform line loads at the location of the contact zone between bolt head and fixing legs. (7) No time dependent behavior, for either the TIM or the equipment, is considered. Although TIMs have creep behavior, simulations have show that these effects are secondary. (8) The heat transfer is steady state, without radiation or convection, since radiation is negligible compared to the heat transferred by conduction and convection does not take place because of the vacuum environment in space. (9) The contact resistance is only pressure dependent. Other dependencies are secondary.

\subsection{Mechanical Model}

\subsubsection{Equipment}

The equipment is modeled with a one-dimensional elastic beam. The beam elements have two degrees of freedom (DOFs): vertical displacement $v$ and rotation angle $\theta$. Figure 5 illustrates one element with nodal forces and DOFs. 


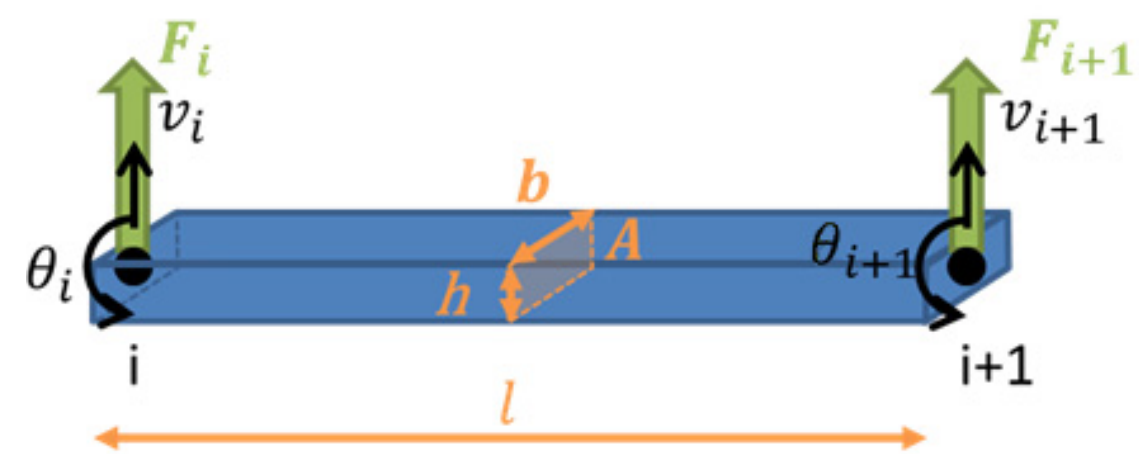

Figure 5. Representation of a mechanical beam element

If Euler-Bernoulli assumptions are used, the equations governing the behavior of the element, written in matrix notation, are given by Eq.1 and Eq.2, below.

$$
\frac{E I_{z}}{l^{3}}\left[\begin{array}{cccc}
12 & 6 l & -12 & 6 l \\
6 l & 4 l^{2} & -6 l & 2 l^{2} \\
-12 & -6 l & 12 & -6 l \\
6 l & 2 l^{2} & -6 l & 4 l^{2}
\end{array}\right]\left[\begin{array}{c}
v_{i} \\
\theta_{i} \\
v_{i+1} \\
\theta_{i+1}
\end{array}\right]=\left[\begin{array}{c}
T_{y i} \\
M_{z i} \\
T_{i y+1} \\
M_{z i+1}
\end{array}\right]
$$

noted as:

$$
\left[\begin{array}{cc}
K_{1}^{e} & K_{2}^{e} \\
K_{3}^{e} & K_{4}^{e}
\end{array}\right]\left[\begin{array}{c}
v_{i} \\
\theta_{i} \\
v_{i+1} \\
\theta_{i+1}
\end{array}\right]=\left[\begin{array}{c}
T_{y i} \\
M_{z i} \\
T_{y i+1} \\
M_{z i+1}
\end{array}\right]
$$

with $E$ the Young's modulus of the material, $I_{z}$ the area moment of inertia about the $z$ axis, $l$ the length of the element, $T_{y}$ and $M_{z}$ the nodal forces and moments. The area moment of inertia is found by means of Eq. 3 .

$$
I_{z}=\frac{b h^{3}}{12}
$$

with $b$ the width and $h$ the height of the element. In general, the central part of the equipment has a particular structure, for example with internal walls, and it is necessary, at this stage, to calculate an equivalent moment of inertia, that is to say one that offers an equivalent bending stiffness. The fixing lugs also have their own stiffness, which is generally low compared to that of the body.

Elements are assembled with one another, leading to a global stiffness matrix given by Eq.4.

$$
[K]=\left[\begin{array}{cccccccc}
K_{1}^{1} & K_{2}^{1} & 0 & & & & & \\
K_{3}^{1} & K_{4}^{1}+K_{1}^{2} & K_{2}^{2} & \ldots & & 0 & \\
0 & K_{3}^{2} & K_{4}^{2}+K_{1}^{3} & & & & & \\
& & \vdots & & \ddots & & \vdots & \\
& & & & & K_{4}^{n-2}+K_{1}^{n-1} & K_{2}^{n-1} & 0 \\
& & & & \cdots & K_{3}^{n-1} & K_{4}^{n-1}+K_{1}^{n} & K_{2}^{n} \\
& & & & 0 & & K_{3}^{n} & K_{4}^{n}
\end{array}\right]
$$


The linear elastic behaviour of the equipment is given by Eq. 5 .

$$
[K]\{U\}=\{F\}
$$

with the displacement vector given by Eq. 6 .

$$
U=\left[\begin{array}{lllllll}
v_{1} & \theta_{1} & v_{2} & \theta_{2} & \ldots & v_{n} & \theta_{n}
\end{array}\right]^{T}
$$

The loading vector, $F$, depends on the TIM and the fasteners.

\subsection{2. $T I M$}

The TIM is modelled by an elastic foundation based on the Winkler model [18]. The Winkler foundation consists of individual springs attached to the nodes of the stepped beam. Since TIMs have nonlinear mechanical behavior due to the presence of polymers, the linear Winkler model is modified to take such behavior into account. The springs are independent of each other; hence no shear interaction is considered between two successive springs. Figure 6 represents one spring element of the elastic foundation. One node is fixed at the level of the rigid surface (satellite support), while the other, which belongs to the meshing of the equipment, is located between two successive beam elements. When the support is taken to be infinitely rigid - the assumption used here the displacements of the nodes placed on this support are zero, and it is not useful to make the spring elements appear as elements present in the reference mesh. It is enough to include their action in the external forces undergone by the equipment.

From the results of an experimental study of the thin layer of polymeric TIM of interest [19], a power law was chosen to model the nonlinear behavior of the material, as given by Eq. 7.

$$
\sigma=a \varepsilon^{b}
$$

where $\sigma$ is a uniaxial compressive stress, $\varepsilon$ the associated deformation, and $a$ and $b$ are characteristics of the material. From this property, a relationship can be established to relate the force exerted by a spring (representing a foundation portion) as a function of displacement on the surface. First, it will be assumed that the spring acts either in compression or in tension, exerting a restoring force which always opposes the displacement as in Eq. 8.

$$
F_{f i}=-a A\left(\frac{v_{i}}{e}\right)^{b} \text { if } v_{i}>0 \text { (tensile), else } F_{f i}=a A\left(\frac{\left(-v_{i}\right)}{e}\right)^{b} \text { (compressive) }
$$

where $A$ is the surface area of the elastic foundation per spring element, $v_{i}$ the vertical translation of node $i$ (cf. Eq. 1 ) and $e$ the initial thickness of the TIM layer. The force $F_{f} i$ exerted by the elastic foundation is to be considered among the external forces (loading vector $F$ of Eq. 5) that act on node $i$ of the equipment in the $y$ direction, with respect to the degree of freedom $v_{i}$. 

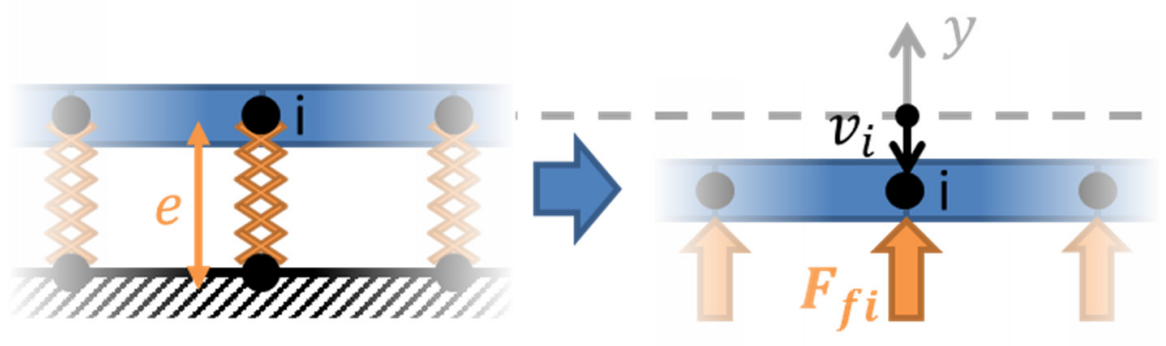

Figure 6. Representation of an elastic foundation element

\subsubsection{System of equations associated with the model}

Figure 7 illustrates the loading applied to the equipment. To the forces exerted by the foundation (those of the TIM, located under the nodes) are added the external loads induced by the fasteners, located above the legs. These bolt loads are distributed over several nodes (e.g. nodes 2, 3 and 4 , which undergo the forces $F_{b 2}, F_{b 3}$ and $F_{b 4}$ ). If contact is lost between the equipment and TIM at a node, the associated force is set to zero (e.g. nodes 8 and 9). The whole system of equations is given by Eq. 9.

$[K]\{U\}=\left\{F_{f}(U)\right\}+\left\{F_{b}\right\}$

where $\left\{F_{f}\right\}$ represents all the forces induced by the elastic foundation and $\left\{F_{b}\right\}$ the forces from the bolts. Finally, the set of equations associated with the proposed model takes the form given in Eq. 10.

$$
[K]\left[\begin{array}{c}
\vdots \\
v_{i} \\
\theta_{i} \\
v_{i+1} \\
\theta_{i+1} \\
\vdots
\end{array}\right]=\frac{a A}{e^{b}}\left[\begin{array}{c}
\vdots \\
\delta_{i}\left|v_{i}\right|^{b} \\
0 \\
\delta_{i+1}\left|v_{i+1}\right|^{b} \\
0 \\
\vdots
\end{array}\right]+\left[\begin{array}{c}
\vdots \\
F_{b i} \\
0 \\
F_{b i+1} \\
0 \\
\vdots
\end{array}\right] \text { where } \delta_{i}=-1 \text { if } v_{i}>0 \text {, else } \delta_{i}=1
$$

with $\delta_{i}$ a parameter having a sign opposite to that of the displacement $v_{i}$, such that negative displacements (compression of the TIM) are equal to positive stresses (compression) and vice versa. Some nodes can have negative stresses (tension). This status is temporary and nodes in tension are disconnected later on when the contact status is verified.

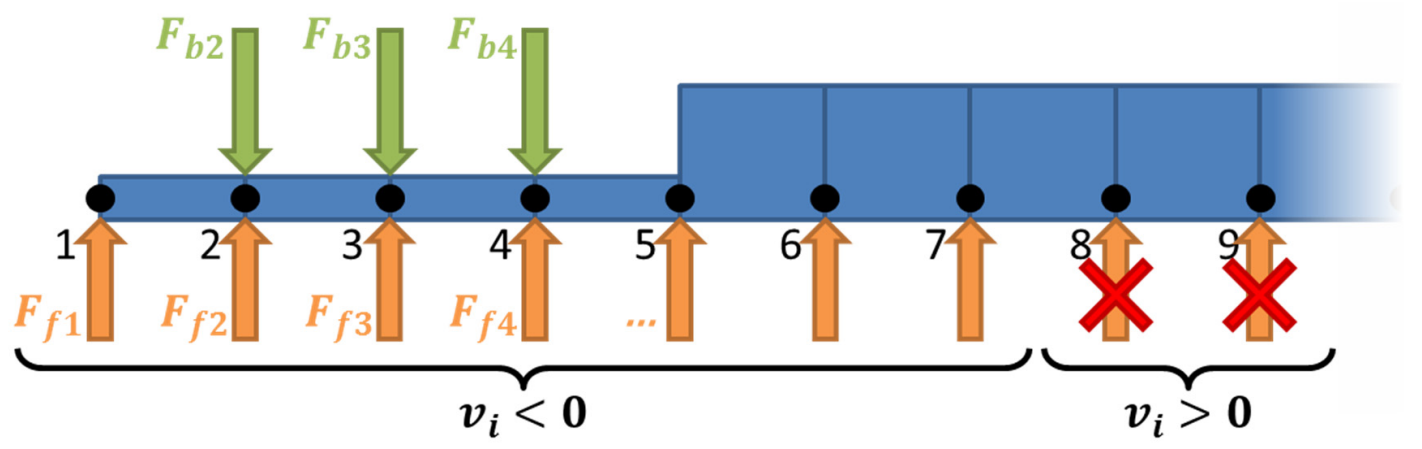


Figure 7. Mechanical model: forces acting on beam nodes

\subsubsection{Solving the system}

2.1.4.1. Loop calculating the displacements

The set of equations to be solved is nonlinear due to the power law characterizing the behavior of the foundation. Variables $v_{i}$ are present in a linear form on the left-hand side of equation 10, and in a nonlinear form on the right-hand side. Therefore, an iterative method is needed to solve the system [20]. The set of equations can be written as Eq. 11.

$$
\{G(U)\}=[K]\{U\}-\left\{F_{f}(U)\right\}-\left\{F_{b}\right\}=0
$$

A root-finding algorithm is used to solve this set of equations. The Newton-Raphson method for systems of nonlinear equations is implemented. The Jacobian matrix $J$ to be considered is given by Eq. 12 .

$$
J(U)=[K]-\frac{a b A}{e^{b}}\left[\begin{array}{cccccc}
\ddots & \vdots & \vdots & \vdots & \vdots & \ddots \\
\ldots & \delta_{i}\left|v_{i}\right|^{b-1} & 0 & 0 & 0 & \ldots \\
\ldots & 0 & 0 & 0 & 0 & \ldots \\
\ldots & 0 & 0 & \delta_{i+1}\left|v_{i+1}\right|^{b-1} & 0 & \ldots \\
\ldots & 0 & 0 & 0 & 0 & \ldots \\
\ddots & \vdots & \vdots & \vdots & \vdots & \ddots
\end{array}\right]
$$

The initial value of the components of the displacement vector is arbitrarily fixed at $0.001 \mathrm{~mm}$, which corresponds to a slightly distorted configuration, this starting point $\left\{\left.U\right|_{0}\right\}$ having no influence on the final result. The first iteration consists in calculating the correcting increment $\left\{\left.H\right|_{1}\right\}$ using Eq. 13, and then adding it to the displacement vector to obtain a new estimate $\left\{\left.U\right|_{1}\right\}$ of this vector (Eq. 14).

$$
\begin{gathered}
\left\{\left.H\right|_{j+1}\right\}=-\left[\left.J\right|_{j}\right]^{-1}\left\{\left.G\right|_{j}\right\} \\
\left\{\left.U\right|_{j+1}\right\}=\left\{\left.U\right|_{j}\right\}+\left\{\left.H\right|_{j+1}\right\}
\end{gathered}
$$

Eqs. 12 to 14 are iterated and convergence is achieved when $\{H\}$ is sufficiently small. The solution converges after only a few iterations.

\subsubsection{Loop controlling the contact status}

The TIM layer is not an adhesive. Thus no tensile stress has to be exerted on the beam when it deflects away from the TIM. If, after a calculation based on the assumption that a contact exists at a certain node, it appears that the interactions correspond to a tensile state, then this hypothesis must be modified: the contact must be considered as lost, and interactions seen as nonexistent at this location. 


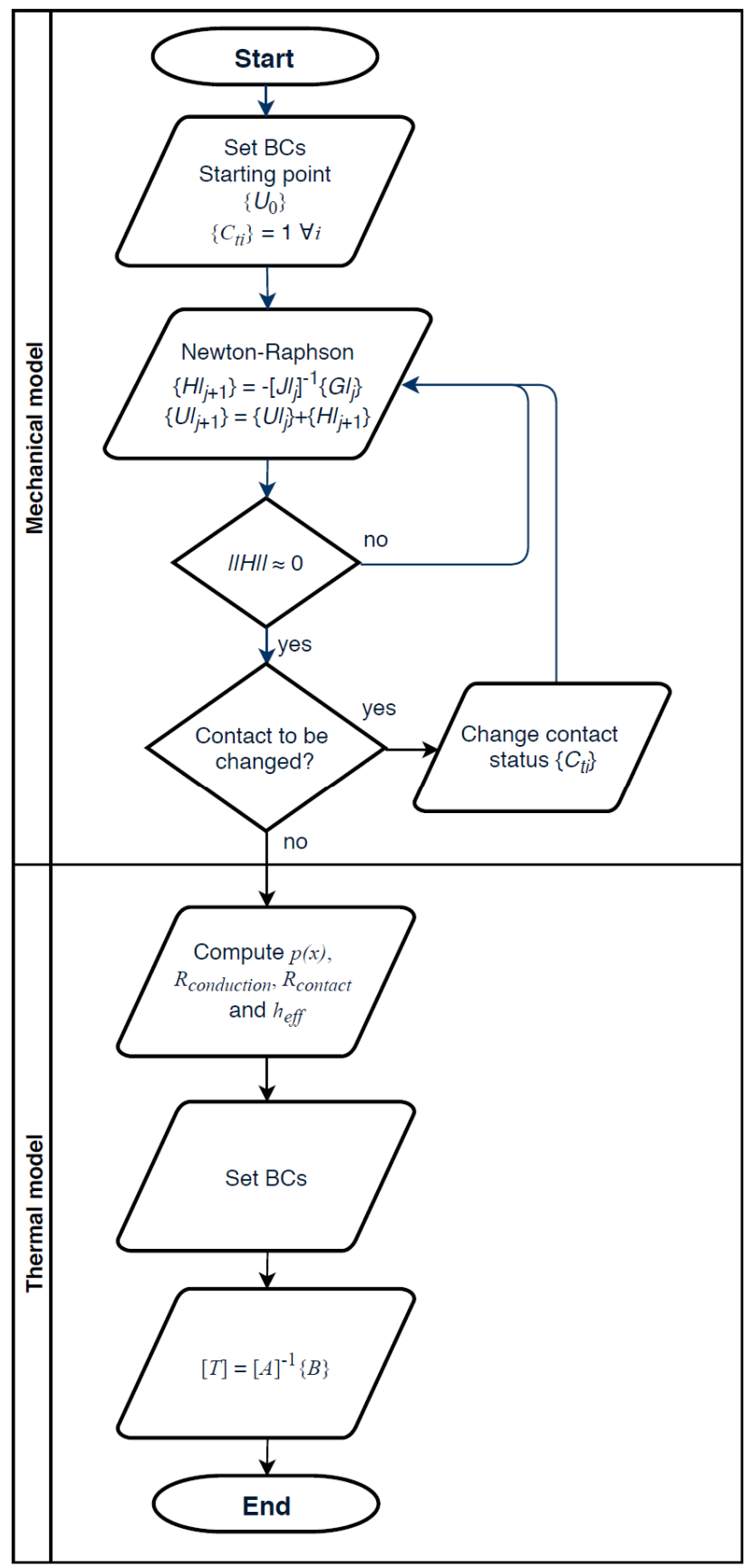

Figure 8. Flow chart of the algorithm

A vector $\left\{C_{t}\right\}$ is used to materialize the contact status considered at a given stage of the global procedure (Eq. 15).

$$
C_{t i}=1 \text { if the contact is present at node } i \text {, else } C_{t i}=0
$$

At the beginning, the equipment is assumed not to be deformed, so all nodes are in contact with the TIM $\left(C_{t i}=1 \forall i\right)$. After the first calculation of the displacements, using 
the Newton-Raphson process seen earlier, the algorithm can establish a new proposition for the contact status (Eq. 16), related to the sign of the $F_{f i}$ obtained.

$$
\text { if } F_{f i}<0 \text { then } C_{t i} \text { must be modified to } 0
$$

A new calculation of the displacements can be performed, ignoring the action of the foundation on the beam at the node where $C_{t i}=0$.

The Newton-Raphson process is repeated until the contact status has converged. Usually, only a few iterations are needed. The algorithm is illustrated by Figure 8 . It consists of two nested loops: the displacement calculation loop is encapsulated in the loop that controls the contact status.

\subsection{Thermal Model}

The thermal model consists of one-dimensional steady state heat transfer elements described by the Laplace heat conduction equation [21]. Figure 9 illustrates one thermal element. A heat generation term allows dissipating electronic components to be taken into account at the elements were they are located (Poisson heat conduction equation). The TIM is modelled by a conductive term, only active at the elements where the equipment is in contact with the TIM.

\subsubsection{Equipment}

The Poisson heat conduction equation, given by Eq. 17, consists of three terms describing conduction, heat generation and conductive coupling by TIM, respectively.

$$
\frac{1}{A} \frac{d}{d x}\left(\lambda A \frac{d T}{d x}\right)+\frac{Q_{e}}{A d x}-\frac{h_{e f f} b d x}{A d x}\left(T-T_{S}\right)=0
$$

with $\mathrm{A}$ the heat transfer surface area perpendicular to the $x$ direction, $\lambda$ the thermal conductivity of the material of the equipment, $Q_{e}$ the heat energy released per element, $b$ the width of the heat transfer surface area along the $z$ direction, $h_{\text {eff }}$ the effective convection coefficient discussed in the following section, and $T_{s}$ the temperature of the heat sink. The heat generation term is different from zero for all elements where the dissipating components are located. The convective term is different from zero for all elements in contact with the TIM, in accordance with the contact status obtained from the previous mechanical step. The differential equation (17) can be solved numerically using the finite difference method, a discretization method conventionally used in very numerous fields [22], for example in vibrations and ultrasonics [23, 24]. Here, the derivatives are approximated by centered finite differences as given by Eq. 18 .

$$
\lambda \frac{T_{i+1}-2 T_{i}+T_{i-1}}{\Delta x^{2}}+\frac{Q_{e}}{\mathrm{~A} \Delta x}-\frac{h_{e f f} b \Delta x}{A \Delta x}\left(T_{i}-T_{S}\right)=0
$$

Eq. 18 can be written in matrix notation as in Eq. 19. 


$$
\left[\begin{array}{lll}
1 & -\left(2+\frac{\Delta x^{2} h_{e f f} b}{A \lambda}\right) & 1
\end{array}\right]\left[\begin{array}{c}
T_{i-1} \\
T_{i} \\
T_{i+1}
\end{array}\right]=\left[\frac{\Delta x^{2} h_{e f f} b}{A \lambda} T_{S}+\frac{Q_{e} \Delta x}{A \lambda}\right]
$$

To make the 1D model even more efficient, it is interesting to model the phenomenon of thermal constriction that occurs in the device. The heat flow must pass from the body of the equipment, which is rather massive, to the fixing lugs, which have small dimensions. The section to be crossed is thus considerably reduced as shown in Figure 1 but the influence of this constraint is not yet taken into account in Eq. 19. Referring to the literature, the obstacle related to the passage from a very large section to a small circular section of diameter $d$ may be modeled using a thermal constriction resistance, its value being calculated according to Eq. 20 [21].

$$
R_{\text {constriction }}=\frac{1}{\sqrt{\pi} d \lambda}
$$

The constriction resistance $R_{\text {constriction }}$ is distributed uniformly over all nodes of the equipment because the restriction of the heat flux extends over a large region. Between two nodes, a resistance $R^{*}$ constriction is added. The finite difference heat transfer equation is given by Eq. 21 and the matrix notation by Eq. 22 .

$$
\begin{aligned}
& \lambda \frac{T_{i+1}-2 T_{i}+T_{i-1}}{\Delta x^{2}+A \Delta x \lambda R^{*} \text { constriction }}+\frac{Q_{e}}{\mathrm{~A} \Delta x}-\frac{h_{e f f} b \Delta x}{A \Delta x}\left(T_{i}-T_{S}\right)=0 \\
& {\left[1-\left(2+\frac{\Delta x^{2} h_{e f f} b}{A \lambda}\left(1+\frac{A \lambda R^{*}{ }_{\text {constriction }}}{\Delta x}\right)\right) \quad 1\right]\left[\begin{array}{c}
T_{i-1} \\
T_{i} \\
T_{i+1}
\end{array}\right]} \\
& =\left[\frac{\Delta x^{2} h_{e f f} b}{A \lambda} T_{s}+\frac{Q_{e} \Delta x}{A \lambda}\right]\left(1+\frac{A \lambda R^{*}{ }_{\text {constriction }}}{\Delta x}\right)
\end{aligned}
$$

Figure 10 illustrates the thermal model. The same mesh is used as for the mechanical calculation. At nodes belonging to elements where there is a change of section, the average width, $B$, and surface area, $A$, are calculated. An $n \times n$ matrix is built and the boundary conditions are implemented. The system of linear equations is computed directly, leading to the temperature distribution along the equipment.

\subsection{2. $T I M$}

Heat transfer through an interface is a complex phenomenon since the Thermal Contact Resistance (TCR) depends on various thermal, geometrical and mechanical parameters, as presented in [6]. For this model, the heat transfer through the TIM nodes in contact with the equipment is modeled by a conductive heat transfer term. The conductive term takes the total thermal resistance into account, including the conductive thermal resistance of the TIM and the two contact resistances at the equipment/TIM and $\mathrm{TIM} /$ heatsink interfaces. The TCR has a very strong dependency on contact pressure [25] 
and is calculated by a power law given by Eq. 23, which is similar to the relations for thermal greases, phase change materials and polymeric materials as in [26] and [27].

$$
R_{\text {contact }}=\alpha \sigma^{\beta}
$$

where $\alpha$ and $\beta$ are constants and $\sigma$ is the contact pressure. The constants depend on various parameters, such as the surface waviness and roughness, hardness, etc. of the two materials in contact. They can be found by experimental characterization as described by Yaoqu Xian et al [28]. Once the mechanical solution has been computed, the contact pressure is calculated by Eq. 7 for all nodes in contact, in order to calculate the TCR. The conductive thermal resistance is found by Eq. 24 .

$$
R_{\text {conduction }}=\frac{t}{\lambda_{T I M}}
$$

with $\lambda_{\text {TIM }}$ the thermal conductivity and $t$ the thickness of the TIM. The thickness is the deformed thickness calculated by the mechanical model. The thermal conductivity can by characterized by several methods as in [29]. The total effective convection coefficient is then found by adding the three thermal resistances (Figure 9) in series as indicated by Eq. 25.

$$
h_{\text {eff }}=\left(R_{\text {contact }}+R_{\text {conduction }}+R_{\text {contact }}\right)^{-1}
$$

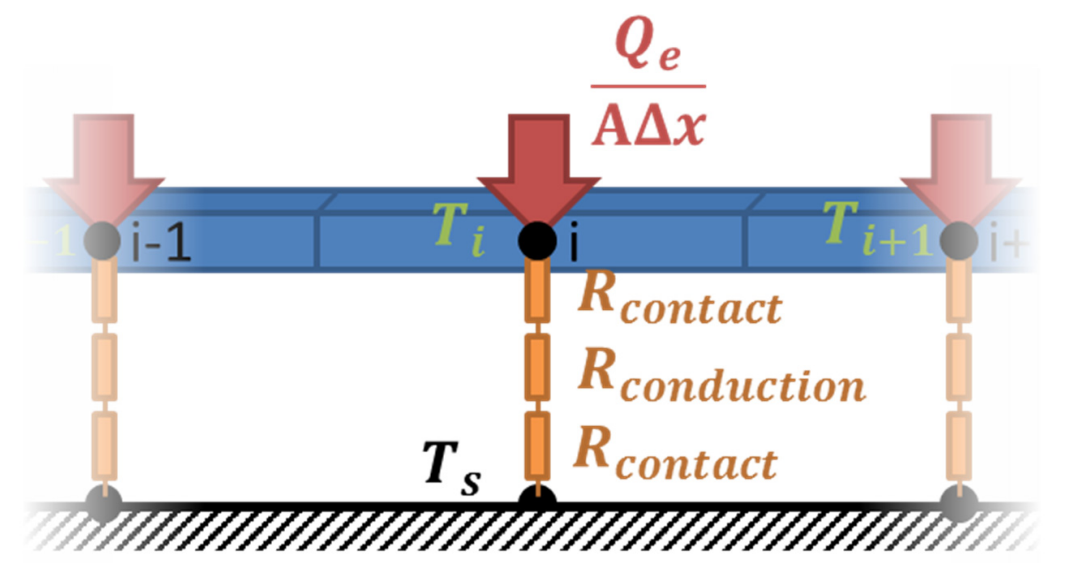

Figure 9. Representation of a thermal element

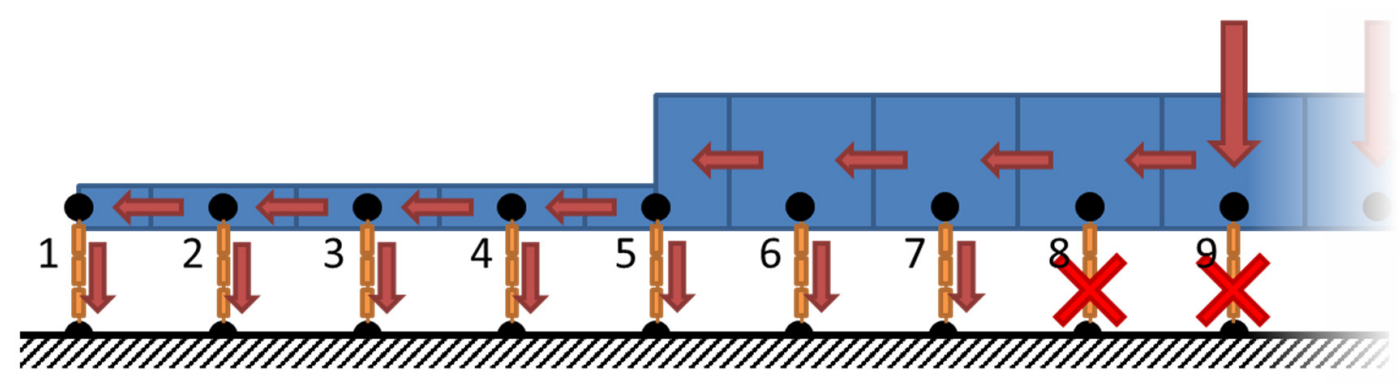

Figure 10. Thermal model: heat conduction through equipment and TIM 


\section{EVALUATING THE PERFORMANCE OF THE 1D MODEL}

The quality of the results that the 1D model can obtain is presented below with reference to an example representative of a range of equipment encountered in the space industry. Figure 11 gives the 3D model of the equipment selected as a test case. The geometry has two perpendicular symmetry planes. This equipment is attached to the receiving structure by 6 bolts. Shape details have been deliberately eliminated to define a test case that is easier to represent.

Useful parameters related to this test case are given in Tables 1 and 2.
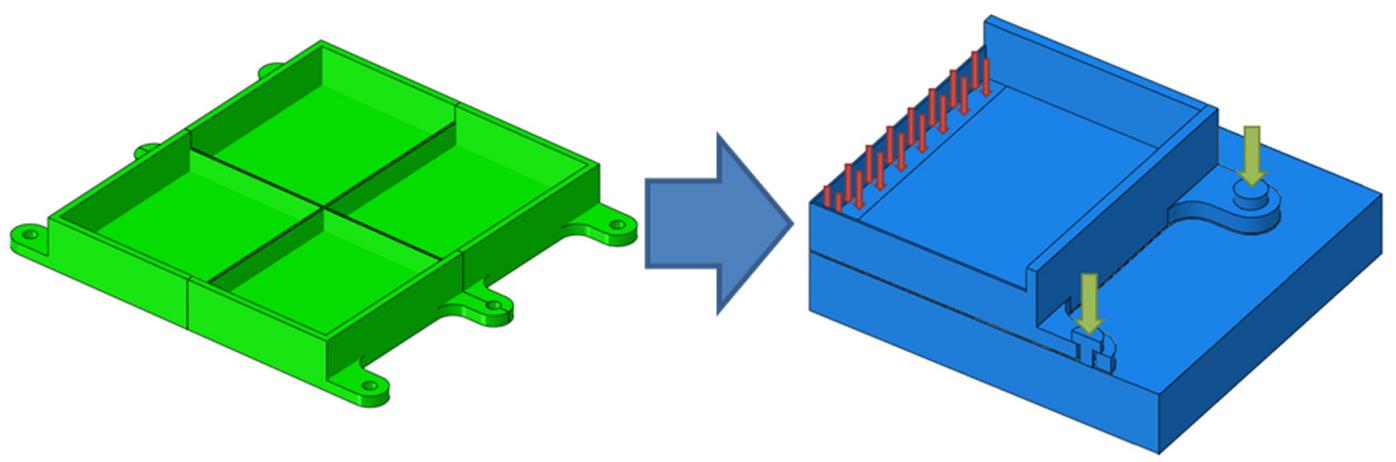

Figure 11. 3D model of the test case

\subsection{About the associated 1D model}

In accordance with the principles of construction of the 1D model described in the previous part, the geometry of the central part of the equipment, including its pockets and stiffeners, is simplified to a solid beam. The width of this beam remains equal to the real width of the equipment. In order for the beam to correctly represent the mechanical bending behavior of this complex body, its height must lead to an equivalent bending stiffness. The second moment of area, also known as moment of inertia of the plane area, is a geometrical parameter allowing the equivalent height to be reached, this moment being accessible by calculation starting from the 3D geometry, or from a CAD model. In our example, a height of $6.55 \mathrm{~mm}$ was found. For the thermal calculation, the height of the bottom of the equipment, equal to $4 \mathrm{~mm}$, was maintained, because we considered a configuration where the stiffeners and the side walls contributed only very little to the heat transfer, the assumption being that the electronic components transmitted their heat directly to a particular area of the bottom wall.

Table 1. Test case for mechanical parameters

\begin{tabular}{|c|c|}
\hline Dimensions of the central part & $\begin{array}{l}\text { Mechanical : } 120 \times 130 \times 6.55 \mathrm{~mm} \\
\text { Thermal : } 120 \times 130 \times 4 \mathrm{~mm}\end{array}$ \\
\hline One fixing leg & 12x18x4 mm (3 legs per side) \\
\hline TIM thickness & $0.38 \mathrm{~mm}$ \\
\hline
\end{tabular}




\begin{tabular}{|l|l|}
\hline Bolt load & $3000 \mathrm{~N}$ (per bolt) \\
\hline Width of load zone & $4 \mathrm{~mm}$ \\
\hline Young's modulus of equipment & $74000 \mathrm{MPa}$ \\
\hline TIM stiffness parameter a & $3290.75 \mathrm{MPa}$ \\
\hline TIM stiffness parameter b & 2.455 \\
\hline
\end{tabular}

Table 2. Test case for thermal parameters

\begin{tabular}{|l|l|}
\hline Heat power & $100 \mathrm{~W}$ \\
\hline Heat sink temperature & $20{ }^{\circ} \mathrm{C}$ \\
\hline Width of dissipating component & $20 \mathrm{~mm}$ \\
\hline Thermal conductivity of equipment & $134 \mathrm{~W} / \mathrm{mK}$ \\
\hline Thermal conductivity of TIM & $2.6 \mathrm{~W} / \mathrm{mK}$ \\
\hline Contact resistance parameter $\alpha$ & 67.0 \\
\hline Contact resistance parameter $\beta$ & -0.563 \\
\hline
\end{tabular}

\subsection{Verification of the Matlab script}

The 1D model was implemented in the Matlab environment to produce a prototype of the design assistance tool that was being sought. To show that this implementation worked correctly, its results are compared below with those obtained when this same 1D model was developed within a commercial code dedicated to the finite element calculation. The thermal constriction resistance was set to zero, as this resistance is not a $1 \mathrm{D}$ resistance but a resistance caused by the heat flux component perpendicular to the 1D direction. Using the FE software Abaqus, a 1D model was built with Euler-Bernoulli beam elements. The TIM was modeled by nonlinear spring elements attached to each node of the beam. Management of the contact was manual: after each resolution, the sign of the displacement of each node of the beam was analyzed and the spring placed in front of the node was kept attached in the case where this displacement was negative; otherwise it was detached. The calculation was repeated as long as changes were needed. The discrepancies observed when comparing displacements and contact pressures obtained from the two calculation tools were almost zero, although, punctually, an error of less than $1 \%$ was observed. The small differences were due to the fact that the nonlinear stiffness of the elastic foundation was modeled in Abaqus by means of a table of discretized values and not by an analytical function. Afterwards, the implementation of the thermal code was verified by a 1D thermal model built in Abaqus. The nodes in contact with the TIM were then manually connected with the heat sink by a thermal resistance. Each thermal resistance was calculated by Eqs. 23 and 24. The BC were set and the results were computed. The same temperature differences between the heat sink and each node were found, with less than $0.03 \%$ error.

\subsection{Comparison with the results of a detailed 3D model}

A refined 3D model was built in Abaqus to examine the capabilities of the 1D model. Both the equipment and the TIM layer were modeled using 3D solid elements, as illustrated in 
Figure 11. The TIM mechanical behavior was represented using the parallel rheological framework proposed in Abaqus, taking both the viscous and the hyperelastic-plastic nature of this material into account. The identification of parameters useful for the description of the material was the subject of a relatively extensive test campaign, not presented here. After analysis, it was found that the viscous nature of the TIM materials under study was weak and that the influence of this characteristic on the phenomena considered remained very low, thus justifying its being ignored in the 1D model.

The bolts were also modeled (Figure 11), including the setting up of their preload. A heat flux was distributed on a particular area of the bottom plate, located at the central part of the equipment (Figure 11). The base plate temperature was fixed at $20{ }^{\circ} \mathrm{C}$. The 3D model was solved using the "Coupled Temperature-Displacement" procedure available in Abaqus, the results being time dependent since the TIM had a viscous behavior. The model was run until the temperatures had stabilized (Figure 12). Figure 13 compares the contact pressure and temperature distributions obtained by the 3D model (Figure 12) with those from the 1D model. Pressures related to the 3D model are given at the median plane of the equipment on the one hand, and at the level of the outer lateral face on the other. Temperatures were measured at the mid-plane of the lower wall, both at the median plane and at the outer lateral face. Note that contact was lost over a large part of the initial contact surface due to bending of the equipment. The contact between the TIM and the equipment only started at $45 \mathrm{~mm}$ from the x-symmetry plane, the contact pressure increasing to $35 \mathrm{MPa}$ at the end of the fixing leg. The temperature variations were close: the difference in temperature, $\Delta \mathrm{T}$, between the equipment and the heat sink was about $4.13^{\circ} \mathrm{C}$ in the $\mathrm{x}$-symmetry plane of the equipment and $1.77^{\circ} \mathrm{C}$ at the opposite side near the end of the fixing leg. Although not insignificant, these differences were relatively small, given the large simplifications made to move from 3D to $1 D$. The temperature distribution calculated by the 1D model was slightly lower than that obtained by the detailed model. This was because this model could not reproduce all the phenomena playing a role in heat transfer. In particular, three points can be noted. (1) The legs were modeled by beams, while in reality they have a rather complex geometry with a rounded edge and a hole for the passage of the screw. The cross-section was overestimated by the 1D model, resulting in an underestimated thermal resistance and a lower $\Delta T$ in the leg zone. (2) The heat flow experienced strong section restriction at the passage from the body to the fixing legs. This phenomenon was dependent on many geometrical parameters. An attempt was made to add a uniformly distributed restriction resistance to the elements of the central part of the equipment. The proposed model, deliberately simple, took only the value of the surface of the smallest section (Eq. 20) into account. This was only a rough estimation as the constriction resistance actually depends on the whole geometry of the equipment and fixing legs. The order of magnitude of the influence on $\Delta T_{\max }$ due to the restriction resistance in this particular case was $4.4{ }^{\circ} \mathrm{C}$ (equal to an increase of 9.9\%), thus reducing the relative error between the 1D and 3D model $\Delta T_{\max }$ from $11 \%$ without constriction resistance to $1.5 \%$ with constriction resistance. (3) In the central beam $(0<x<55 \mathrm{~mm})$, the temperature profile of the side edge differed from that of the center edge. The slope of the temperature profile of the side edge was slightly lower. This was caused by the thick side wall of the equipment. 
Some heat flux passes through the side wall, thus reducing the thermal resistance and $\Delta T$. The stiffener in the center is much thinner and less tall then the side wall. The temperature at the center line is thus less influenced by the side wall, and is closer to the 1D model.

Although the 1D model greatly simplifies the geometry and the behavior of the TIM, it is able to produce a sufficiently accurate estimate of the distribution of contact pressure and temperature to allow designers to judge the relevance of their choices.
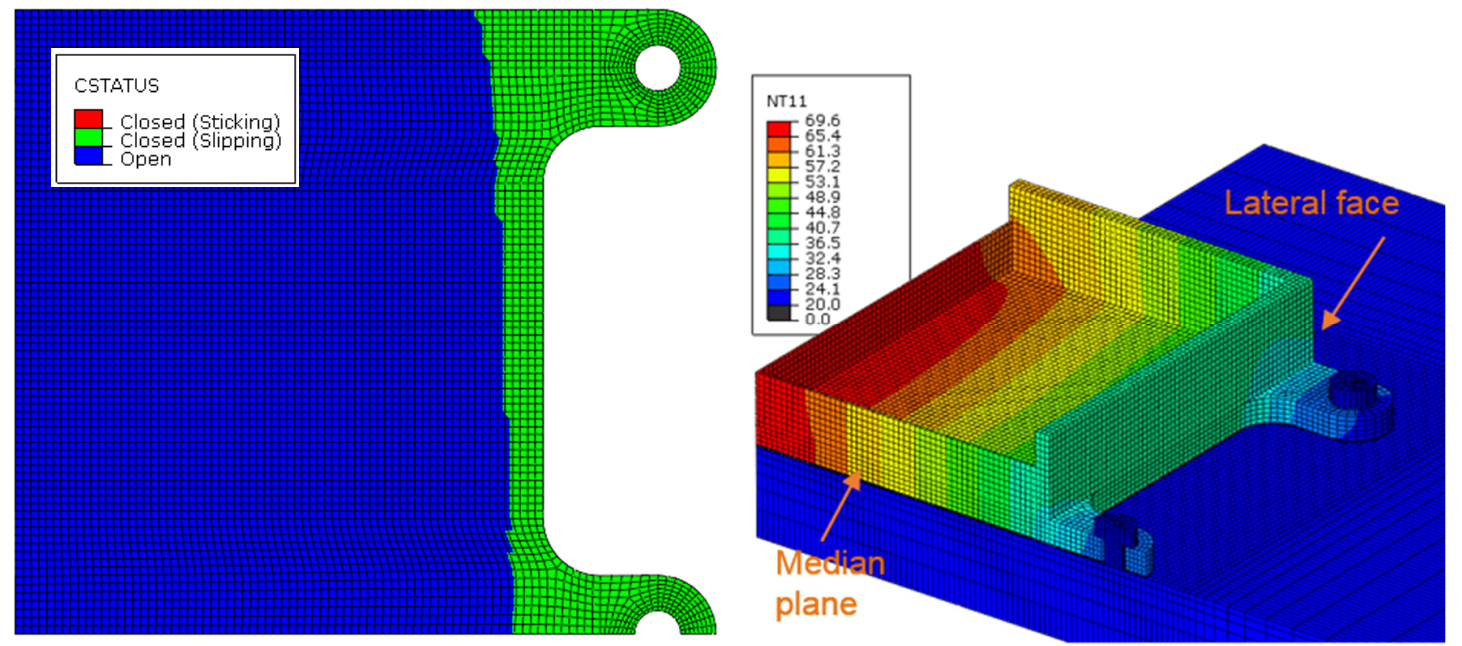

Figure 12. Results of 3D model: contact status (left) and temperature profile (right)

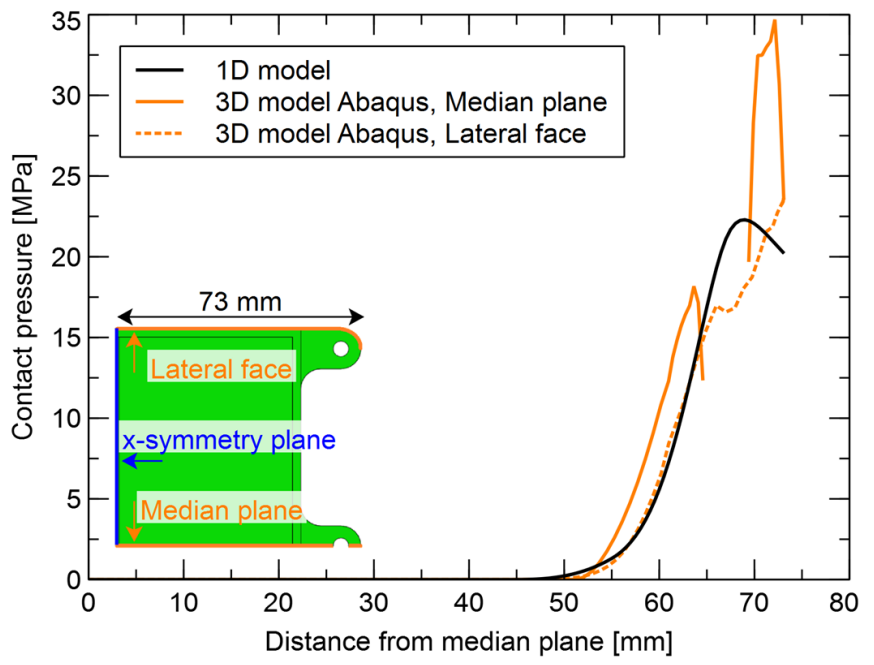




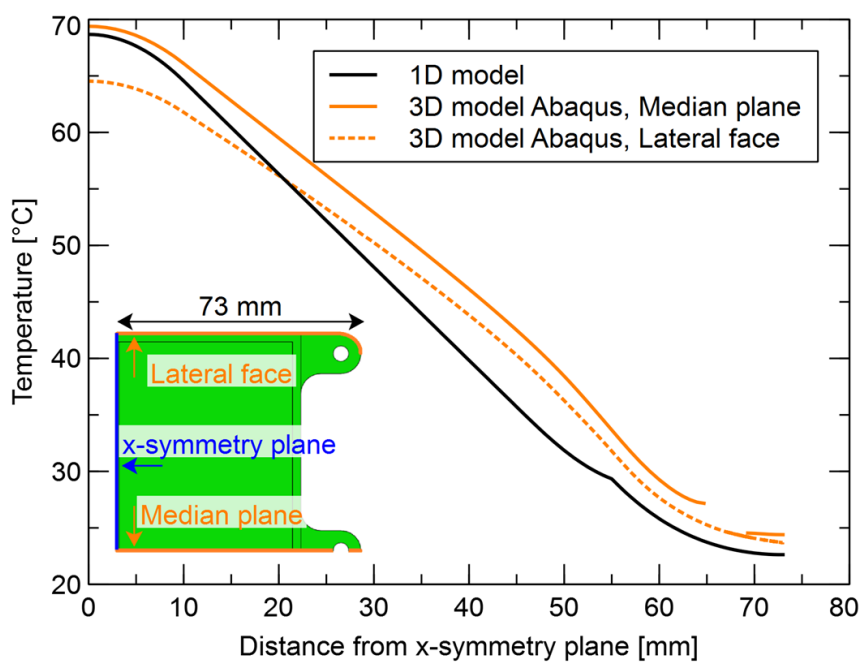

Figure 13. Results of comparison between the 3D model and 1D model: contact pressure (top) and temperature profile (bottom)

\section{EXPLOITATION OF THE MODEL}

This section illustrates the main interest of using such basic 1D models as part of a design assistance tool. Calculation of the test medium described above using the 1D model is iterated for different input parameters to better understand the influencing factors and to identify possible enhancements in thermal performance. For ease of analysis, the parameters are considered two by two. By giving a range of possible variation for each of them, the design space can be discretized, for example by taking 20 intervals between the two limits, and the calculation can be instantiated for each node of this mesh. The improvement or degradation of the thermal performance that can be achieved when the parameters vary is measured against the performance of the test configuration defined above and considered as the reference. The calculation consists in estimating the percentage of relative decrease or increase experienced by the maximum temperature difference $\Delta T$ between the equipment and the heat sink, as given by Eq. 26 .

$$
\operatorname{Perf}_{\Delta T}=\frac{\left(T_{\max }-T_{S}\right)-\left(T_{\text {max }} \text { test } \text { case }-T_{S}\right)}{\left(T_{\text {max }} \text { test } \text { case }^{-T_{S}}\right)} \cdot 100 \%
$$

Figure 14a shows the contour map of the thermal performance variation $\operatorname{Per} f_{\Delta T}$ with respect to the stiffness and thermal conductivity of the TIM. The red dot shown in the figure corresponds to the configuration of the test case (Tables 1 and 2). So it is located on the $0 \%$ contour. Any solution for which the calculated $\operatorname{Per} f_{\Delta T}$ is negative is better than the reference solution, as long as it has a lower maximum temperature than the reference solution. Figure 14A shows that, logically, an increase in the thermal conductivity of the TIM contributes to a decrease in the maximum temperature of the component. These two parameters are the ones by which a TIM is identified. Thus, the designer can directly determine which TIM material would be the best choice. As the plot indicates, a softer and more conductive TIM can increase the performance by $10 \%$. Figure $14 \mathrm{~B}$ relates to two parameters that characterize the material of the equipment. Some common construction materials have been added to the plot. A stiffer and more conductive 
material is needed to gain in thermal performance. Stainless steel is three times stiffer than aluminum ( $200 \mathrm{GPa}$ vs $70 \mathrm{GPa}$ ) but is a poor thermal conductor ( $15 \mathrm{vs} 135 \mathrm{~W} / \mathrm{mK}$ ) and would, therefore, not be a good choice, unlike copper, which is an excellent thermal conductor $(400 \mathrm{~W} / \mathrm{mK})$ and is stiffer than aluminum alloy (115 GPa). From figures $14 \mathrm{~A}$ and $14 \mathrm{~B}$, it is observed that stiffer equipment and softer TIM is needed to improve the test case. This is because a more rigid equipment item will bend less under a given load and a softer TIM will adapt better to the deflected shape, which will result in an increase in the contact area and thus a decrease in maximum temperature. Figure $14 \mathrm{C}$ considers both the thermal conductivity of the TIM and that of the equipment, the objective being to evaluate their relative importance. It turns out that doubling the thermal conductivity of the equipment material leads to a thermal performance gain of $43 \%$, while the gain provided by a perfectly conducting TIM is only $5 \%$. This is because the thermal resistance of the TIM is much lower than that of the equipment because the path traveled inside the equipment is much longer than the thickness of the TIM. Figure 14D shows the influence of the force exerted by the bolts and the thickness of the TIM layer. The graph indicates that, contrary to what one might think intuitively, a gain is possible if the TIM thickness is increased and the bolt load decreased. This is because the contact resistance is highly pressure dependent and adding TIM material lengthens the thermal path inside the TIM, which is, in fact, a poor conductor. However, less force equals less deflection and thicker foundation equals better adaptation, both of which increase the contact area and thus the temperature. Figure 14E varies the height of the central beam and the height of the fixing legs, relatively to the mechanical model (the height is kept at $4 \mathrm{~mm}$ for both heights in the thermal model). It shows that, by stiffening the central beam, a reduction in $\operatorname{Per} f_{\Delta T}$ can be obtained easily, whereas the effect of stiffening the legs is marginal. Stiffening the central part results in less deformation and a larger contact area, thus increasing thermal performance. Figure $14 \mathrm{~F}$ is of the same type as Figure $14 \mathrm{E}$ but the heights are also modified in the thermal model, and set equal to those of the mechanical model. The results are similar to those in Figure $14 \mathrm{E}$, but increasing the thermal height with the mechanical height increases the thermal performance even more because the thermal conduction resistance inside the equipment is directly proportional to the height. The nominal case does not appear in this graph, as the mechanical height of the central beam is not equal to the thermal height, due to the stiffeners. 

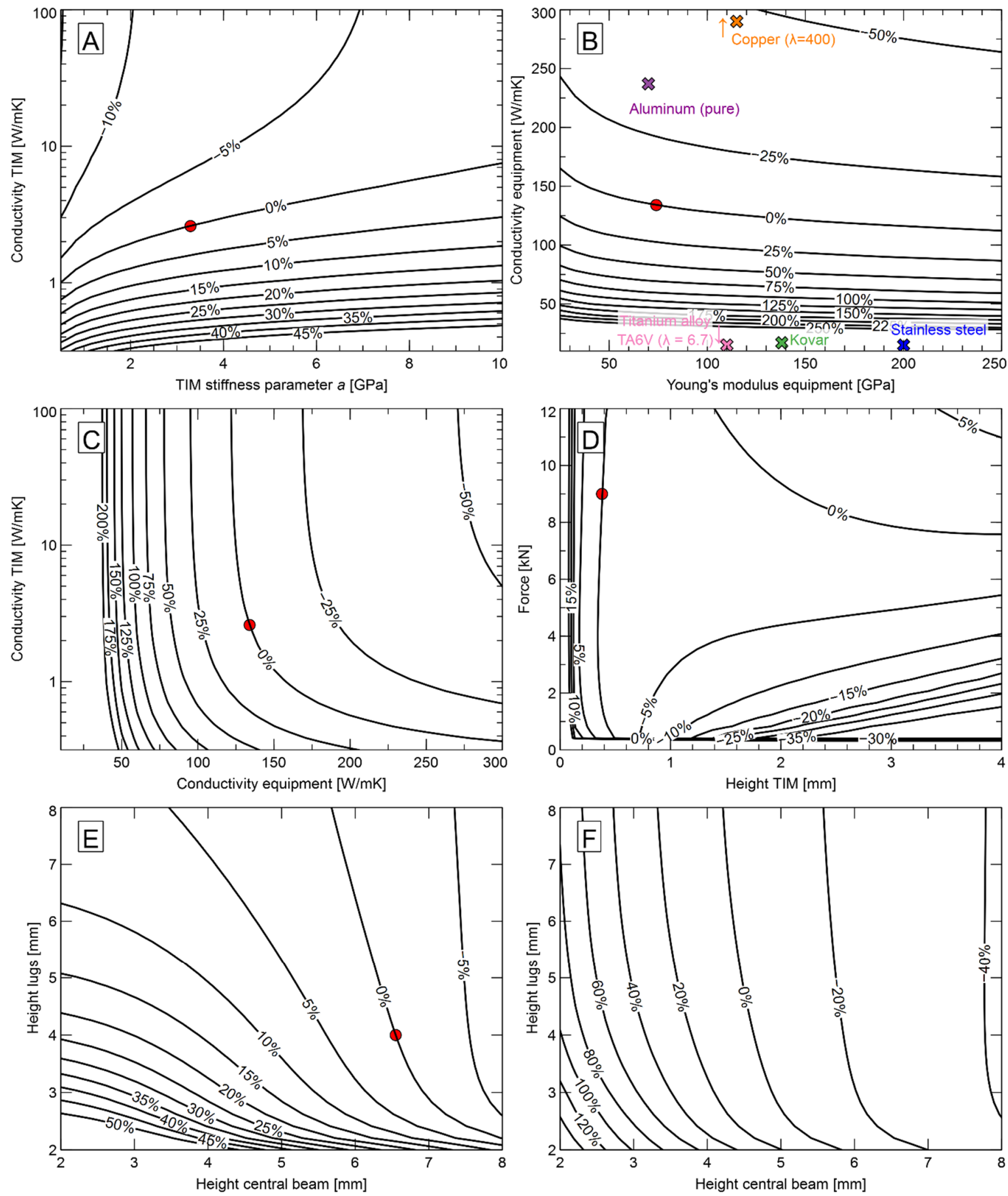

Figure 14. Contour plots of thermal performance $\operatorname{Per} f_{\Delta T}$ for various material and geometry parameters

The analyses presented above indicate the directions to be followed in terms of modification of the geometry and material parameters. However, they also show that the improvements will remain relatively modest: the temperature of the component can only be reduced by a few degrees. Nevertheless, the results obtained make it possible to 
understand that poor results are mainly due to the loss of contact that takes place in a large area located at the central part of the equipment item. Thanks to some quick enhancements, the 1D basic models can be used to study the feasibility of new innovative solutions. We can consider increasing the thickness of TIM in the center of the equipment to overcome the loss of contact in this part. Doing this should reduce the value of $\Delta T$ but is only interesting if the sizing is mastered: what width of TIM and what thickness of TIM should be used in the center to achieve the best results? To explore this solution, the code has been partially rewritten. It is assumed that a patch of TIM will be placed in the center and will be thicker than the parts placed on either side, under the fixing legs. A set of possible TIM widths and possible TIM thicknesses is considered. The model is then used iteratively to explore the performance of each combination, thus providing a good estimate of the influence of the geometry of the central patch. Figure 15 illustrates the evolution of $\operatorname{Per} f_{\Delta T}$ between the new design and the nominal case. For a patch $26.5 \mathrm{~mm}$ long and $0.28 \mathrm{~mm}$ thick, $\operatorname{Per} f_{\Delta T}$ can be reduced by $74 \%$. It can be seen that the gain is not sensitive to the thickness of the patch beyond a minimum value of about $0.1 \mathrm{~mm}$, and is not very sensitive to the width of the patch, which must be between 20 and $30 \mathrm{~mm}$. This solution appears to be very interesting, both by the high gain that it provides and by the fact that it does not require significant precision in terms of dimensioning.

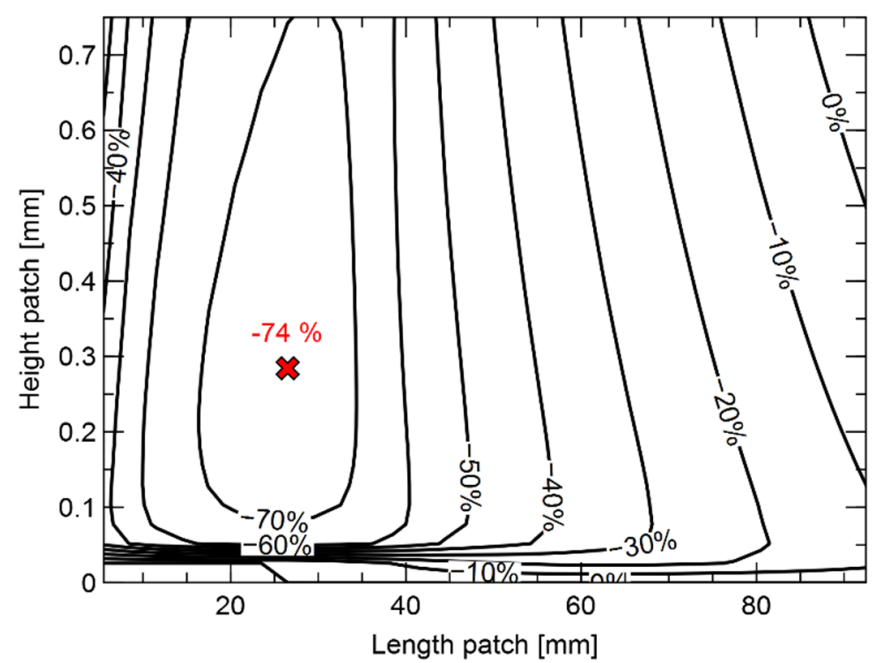

Figure 15. $P \operatorname{erf} f_{\Delta T}$ contour plot with extra TIM patch compared to the nominal case

\section{CONCLUSIONS}

The use of two 1D models in succession, one mechanical and the other thermal, is proposed here to evaluate the thermal performance of an assembly where an item of electronic equipment is connected to a heat sink via a TIM sheet. The initial hypotheses, the founding equations and the resolution algorithm are presented. The proper functioning of a design assistance tool built from the stated principles is verified using commercially available software. The proposed approach calculates the pressure and temperature profiles of the various parts of the assembly. The results from the 1D models are then compared with those of a 3D model, the objective being to evaluate the precision 
that can be obtained despite the simplification made. The differences observed in the pressure and temperature profiles remain low, less than $20 \%$, which is small given the significant simplification achieved in terms of modeling. The region to which the thermal engineer pays the most attention is the region where the temperature reaches its maximum value (place of $\Delta T_{\max }$ ). The $1 \mathrm{D}$ model manages to provide an interesting evaluation in this area, the proposed temperature being in the temperature range of the two limiting planes (lateral face and median plane) obtained by the 3D model. The greatest differences are at the level of the fixing lugs, which are regions of less interest, the $\Delta T$ being much lower there. It should be noted that the 1D model allows, in the case studied, to accurately predict the contact status, which is an essential condition for successfully predicting the temperature distribution. Then, the implementation of the 1D tool in the context of a parametric study shows how it can be of interesting assistance to a user in the design phase. The lessons learned from the results can lead to a reconsideration of the conclusions that one would draw intuitively: for example, contrary to what one might think, significantly increasing the thermal conductivity of the TIM does not increase the thermal performances of the system much - at best by a few percent. As another example, decreasing the clamping forces of the fasteners and increasing the thickness of the TIM sheet may be profitable choices. According to Lasance [8], a designer may have a mistaken perception of the thermal resistance of a system because of the complexity induced by all the phenomena that are combined. Finally, the 1D tool was set up punctually to study the feasibility of a corrective solution: placing a thicker zone of TIM in the center, where the contact would be lost. The results obtained indicate that this is a promising and easy-to-implement solution, reducing $\Delta T$ by as much as $74 \%$ in the test case.

The limits of the proposed 1D approach are mainly related to the geometry of the equipment. The latter must have a plane of symmetry (Figure 1) and its mechanical behavior must be such that it can be reasonably restored by that of a stepped beam subjected to bending. The results are more reliable when the shape of this equipment is elongated and flattened, and when the thermal load to be modeled has the same plane of symmetry. The contact surface with the support must be flat, since any shape singularity at this level would cause contact pressure peaks whose impact would be difficult to assess.

\section{FUNDING}

The author(s) disclosed receipt of the following financial support for the research, authorship, and/or publication of this article: This research is supported by the French space agency (CNES) and Thales Alenia Space (TAS). 


\section{NOMENCLATURE}

\begin{tabular}{|c|c|}
\hline$A$ & Surface area $\left(\mathrm{mm}^{2}\right)$ \\
\hline$a$ & Material stiffness parameter $\left(\mathrm{N} / \mathrm{mm}^{2}\right)$ \\
\hline$B$ & Width $(\mathrm{mm})$ \\
\hline$b$ & Material stiffness parameter (/) \\
\hline CAD & Computer Added Design \\
\hline$C_{t}$ & Contact status variable \\
\hline DOF & Degree Of Freedom \\
\hline E & Young's modulus (MPa) \\
\hline$F$ & Force $(\mathrm{N})$ \\
\hline FEA & Finite Element Analysis \\
\hline$F_{b}$ & Force by bolts $(\mathrm{N})$ \\
\hline$F_{f}$ & Force by elastic foundation $(\mathrm{N})$ \\
\hline$h$ & Height $(\mathrm{mm})$ \\
\hline$h_{e f f}$ & Effective convective heat transfer coefficient $\left(\mathrm{W} / \mathrm{m}^{2} \mathrm{~K}\right)$ \\
\hline$i$ & Node index number \\
\hline Iz & Moment of inertia about $\mathrm{z}$ axis $\left(\mathrm{mm}^{4}\right)$ \\
\hline j & Iteration index number \\
\hline$K$ & Stiffness (N/mm) \\
\hline I & Length $(\mathrm{mm})$ \\
\hline$M$ & Moment (Nm) \\
\hline$n$ & Number of nodes \\
\hline PCB & Printed Circuit Boards \\
\hline $\operatorname{Per} f_{\Delta T}$ & Performance of temperature difference compared to test case (\%) \\
\hline$Q_{e}$ & Heat energy per element (W) \\
\hline$R_{\text {conduction }}$ & Thermal conduction resistance $\left(\mathrm{m}^{2} \mathrm{~K} / \mathrm{W}\right)$ \\
\hline$R_{\text {constriction }}$ & Thermal constriction resistance (K/W) \\
\hline$R_{\text {contact }}$ & Thermal contact resistance $\left(\mathrm{m}^{2} \mathrm{~K} / \mathrm{W}\right)$ \\
\hline$T$ & Temperature $\left({ }^{\circ} \mathrm{C}\right)$ \\
\hline$t$ & Thickness (mm) \\
\hline TCR & Thermal Contact Resistance \\
\hline TIM & Thermal Interface Material \\
\hline Ty & Nodal force $(\mathrm{N})$ \\
\hline$\alpha$ & Thermal contact resistance parameter $\left(\mathrm{m}^{2} \mathrm{~K} / \mathrm{W}\right)$ \\
\hline$\beta$ & Thermal contact resistance parameter (/) \\
\hline$\delta$ & Displacement sign variable \\
\hline$\varepsilon$ & Uniaxial deformation (/) \\
\hline$\theta$ & Rotation angle (degrees) \\
\hline$\lambda$ & Thermal conductivity $(\mathrm{W} / \mathrm{mK})$ \\
\hline$v$ & Vertical displacement $(\mathrm{mm})$ \\
\hline$\sigma$ & Uniaxial compressive stress $\left(\mathrm{N} / \mathrm{mm}^{2}\right)$ \\
\hline
\end{tabular}




\section{REFERENCES}

[1] Pecht, M., 1991, Handbook of Electronic Package Design, CRC Press. ISBN:

9780824779214.

[2] Wang, S., Xie, T., and Xie, H., 2018, "Experimental Study of the Effects of the Thermal Contact Resistance on the Performance of Thermoelectric Generator," Applied Thermal Engineering, 130, pp. 847-853, DOI : 10.1016/j.applthermaleng.2017.11.036.

[3] "Spaceborne S-Band Solid State Power Amplifier - General Dynamics Mission Systems" [Online]. Available:

http://gdmissionsystems.com/products/communications/spacebornecommunications/mission-data-links/s-band-solid-state-power-amplifier. [Accessed: 27Aug-2018].

[4] Prasher, R., 2006, "Thermal Interface Materials: Historical Perspective, Status, and Future Directions," Proceedings of the IEEE, 94(8), pp. 1571-1586, DOI :

10.1109/JPROC.2006.879796.

[5] European Cooperation for Space Standardization, "ECSS-Q-ST-70-02C - Thermal vacuum outgassing test for the screening of space materials (15 November 2008)", ESA Requirements and Standards Division, ESTEC, P.O. Box 299, 2200 AG Noordwijk The Netherlands

[6] Yovanovich, M. M., 2005, "Four Decades of Research on Thermal Contact, Gap, and Joint Resistance in Microelectronics," IEEE Transactions on Components and Packaging Technologies, 28(2), pp. 182-206, DOI : 10.1109/TCAPT.2005.848483.

[7] Bahrami, M., Culham, J. R., Yananovich, M. M., and Schneider, G. E., 2006, "Review of Thermal Joint Resistance Models for Nonconforming Rough Surfaces," Applied Mechanics Reviews, 59(1), p. 1, DOI : 10.1115/1.2110231.

[8] Yovanovich, M. M., and Marotta, E. E., 2003, "Thermal Spreading and Contact Resistances," Heat Transfer Handbook, 1, pp. 261-394. ISBN: 978-0-471-39015-2.

[9] Lasance, C. J. M., 2010, "How to Estimate Heat Spreading Effects in Practice," J. Electron. Packag, 132(3), pp. 031004-031004-7, DOI : 10.1115/1.4001856.

[10] Nakayama, W., 2013, "Study on Heat Conduction in a Simulated Multicore Processor Chip-Part II: Case Studies," J. Electron. Packag, 135(2), pp. 021003-02100316, DOI : 10.1115/1.4023292.

[11] Cheng, J., Zhou, Z., Liu, Z., Zhang, Y., and Tan, J., 2018, “Thermo-Mechanical Coupling Analysis of a High-Speed Actuating Mechanism Based on a New Thermal 
Contact Resistance Model," Applied Thermal Engineering, 140, pp. 487-497, DOI : 10.1016/j.applthermaleng.2018.05.063.

[12] Liu, D.-S., Ni, C.-Y., and Chen, C.-Y., 2003, "Integrated Design Method for Ip Chip CSP with Electrical, Thermal and Thermo-Mechanical Qualifications," Finite Elements in Analysis and Design, 39, pp. 221-235, DOI : 10.1016/S0168-874X(02)00133-6.

[13] Sartre, V., and Lallemand, M., 2001, "Enhancement of Thermal Contact Conductance for Electronic Systems," Applied Thermal Engineering, 21(2), pp. 221-235, DOI : 10.1016/S1359-4311(00)00034-X.

[14] Singh, S., Sørensen, K., and Condra, T. J., 2016, "Influence of the Degree of Thermal Contact in Fin and Tube Heat Exchanger: A Numerical Analysis," Applied Thermal Engineering, 107, pp. 612-624, DOI : 10.1016/j.applthermaleng.2016.07.022.

[15] Bendada, A., Derdouri, A., Lamontagne, M., and Simard, Y., 2004, "Analysis of Thermal Contact Resistance between Polymer and Mold in Injection Molding," Applied Thermal Engineering, 24(14-15), pp. 2029-2040, DOI :

10.1016/j.applthermaleng.2003.12.027.

[16] Li, W., Li, Q., Steven, G. P., and Xie, Y. M., 2003, "An Evolutionary Approach to Elastic Contact Optimization of Frame Structures," Finite Elements in Analysis and Design, 40(1), pp. 61-81, DOI : 10.1016/S0168-874X(02)00179-8.

[17] Basaran, C., Desai, C. S., and Kundu, T., 1998, "Thermomechanical Finite Element Analysis of Problems in Electronic Packaging Using the Disturbed State Concept: Part 1Theory and Formulation," J. Electron. Packag, 120(1), pp. 41-47, DOI : 10.1115/1.2792284.

[18] Hetenyi, M., 1946, Beams on Elastic Foundation; Theory with Applications in the Fields of Civil and Mechanical Engineering, Ann Arbor, The University of Michigan Press. ISBN: 0-472-08445-3.

[19] Vandevelde, S., Daidié, A., and Sartor, M., 2018, "Evaluation and Optimization of Heat Transfer at the Interfaces of Spacecraft Assemblies," CEAS Space Journal, DOI : $10.1007 / \mathrm{s} 12567-018-0226-4$.

[20] Beaufait, F. W., and Hoadley, P. W., 1980, "Analysis of Elastic Beams on Nonlinear Foundations," Computers \& Structures, 12(5), pp. 669-676, DOI : 10.1016/00457949(80)90168-6.

[21] Çengel, Y. A., 2003, Heat Transfer: A Practical Approach, McGraw-Hill. ISBN : 978-007-245893-0. 
[22] Thomas, J.W., 2013, "Numerical Partial Differential Equations: Finite Difference Methods," Springer Science \& Business Media, DOI : 10.1007/978-1-4899-7278-1.

[23] Carrino, S., Nicassio, F., Scarselli, G. and Vitolo, R., 2019, "Finite difference model of wave motion for Structural Health Monitoring of Single Lap Joints," Int. J. of Solids and Structures, 161, pp. 219-227, DOI : 10.1016/j.ijsolstr.2018.11.019.

[24] Sarens, B., Verstraeten, B., Glorieux, C., Kalogiannakis, G., and Van Hemelrijck, D., "Investigation of contact acoustic nonlinearity in delaminations by shearographic imaging, laser doppler vibrometric scanning and finite difference modeling", IEEE Transactions on Ultrasonics, Ferroelectrics and Frequency Control, vol. 57, no. 6, pp. 1383-1395, Jun. 2010, DOI : 10.1109/TUFFC.2010.1557.

[24] Sponagle, B., and Groulx, D., 2016, "Measurement of Thermal Interface Conductance at Variable Clamping Pressures Using a Steady State Method," Applied Thermal Engineering, 96, pp. 671-681, DOI : 10.1016/j.applthermaleng.2015.12.010.

[25] Savija, I., Culham, J. R., Yovanovich, M. M., and Marotta, E. E., 2003, "Review of Thermal Conductance Models for Joints Incorporating Enhancement Materials," Journal of Thermophysics and Heat transfer, 17(1), pp. 43-52, DOI : 10.2514/2.6732.

[26] Bahrami, M., Yovanovich, M. M., and Marotta, E. E., 2006, "Thermal Joint Resistance of Polymer-Metal Rough Interfaces," Journal of electronic packaging, 128(1), pp. 23-29, DOI: 10.1115/1.2159005.

[27] Xian, Y., Zhang, P., Zhai, S., Yuan, P., and Yang, D., 2018, “Experimental Characterization Methods for Thermal Contact Resistance: A Review," Applied Thermal Engineering, 130, pp. 1530-1548, DOI : 10.1016/j.applthermaleng.2017.10.163.

[28] Zhao, D., Qian, X., Gu, X., Jajja, S. A., and Yang, R., 2016, “Measurement Techniques for Thermal Conductivity and Interfacial Thermal Conductance of Bulk and Thin Film Materials," J. Electron. Packag, 138(4), pp. 040802-040802-19, DOI :

10.1115/1.4034605. 